San Jose State University

SJSU ScholarWorks

Master's Theses

Master's Theses and Graduate Research

1998

\title{
Comparison of thrombolytic therapy to anigoplasty for treatment of acute myocardial infarction
}

Joy E. Morris

San Jose State University

Follow this and additional works at: https://scholarworks.sjsu.edu/etd_theses

\section{Recommended Citation}

Morris, Joy E., "Comparison of thrombolytic therapy to anigoplasty for treatment of acute myocardial infarction" (1998). Master's Theses. 1709.

DOI: https://doi.org/10.31979/etd.8r4e-ew5h

https://scholarworks.sjsu.edu/etd_theses/1709

This Thesis is brought to you for free and open access by the Master's Theses and Graduate Research at SJSU ScholarWorks. It has been accepted for inclusion in Master's Theses by an authorized administrator of SJSU ScholarWorks. For more information, please contact scholarworks@sjsu.edu. 


\section{INFORMATION TO USERS}

This manuscript has been reproduced from the microfilm master. UMI films the text directly from the original or copy submitted. Thus, some thesis and dissertation copies are in typewriter face, while others may be from any type of computer printer.

The quality of this reproduction is dependent upon the quality of the copy submitted. Broken or indistinct print, colored or poor quality illustrations and photographs, print bleedthrough, substandard margins, and improper alignment can adversely affect reproduction.

In the unlikely event that the author did not send UMI a complete manuscript and there are missing pages, these will be noted. Also, if unauthorized copyright material had to be removed, a note will indicate the deletion.

Oversize materials (e.g., maps, drawings, charts) are reproduced by sectioning the original, beginning at the upper left-hand comer and continuing from left to right in equal sections with small overlaps. Each original is also photographed in one exposure and is included in reduced form at the back of the book.

Photographs included in the original manuscript have been reproduced xerographically in this copy. Higher quality 6" $\times$ 9" black and white photographic prints are available for any photographs or illustrations appearing in this copy for an additional charge. Contact UMI directly to order.

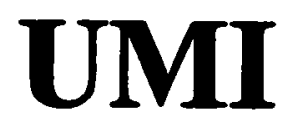

A Bell \& Howell Information Company

300 North Zeeb Road, Ann Arbor MI 48106-1346 USA

$313 / 761-4700 \quad 800 / 521-0600$ 



\section{NOTE TO USERS}

The original manuscript received by UMI contains pages with print exceeding margin guidelines, and slanted print. Pages were microfilmed as received.

This reproduction is the best copy available 



\author{
A Thesis \\ Presented to \\ The Faculty of the Department of Biological Sciences \\ San Jose State University
}

In Partial Fulfillment

of the Requirement for the Degree

Master of Science

by

Joy E. Morris

August 1998 
OMI Number: 1391532

\section{Copyright 1998 by}

Morris, JoY $\mathrm{E}$.

All rights reserved.

\section{UMI Microform 1391532}

Copyright 1998, by UMI Company. All rights reserved.

This microform edition is protected against unauthorized copying under Title 17, United States Code.

\section{UMI}

300 North Zeeb Road

Ann Arbor, MI 48103 
(C) 1998

Joy E. Morris

ALL RIGHTS RESERVED 
APPROVED BY THE DEPARTMENT OF BIOLOGICAL SCIENCES
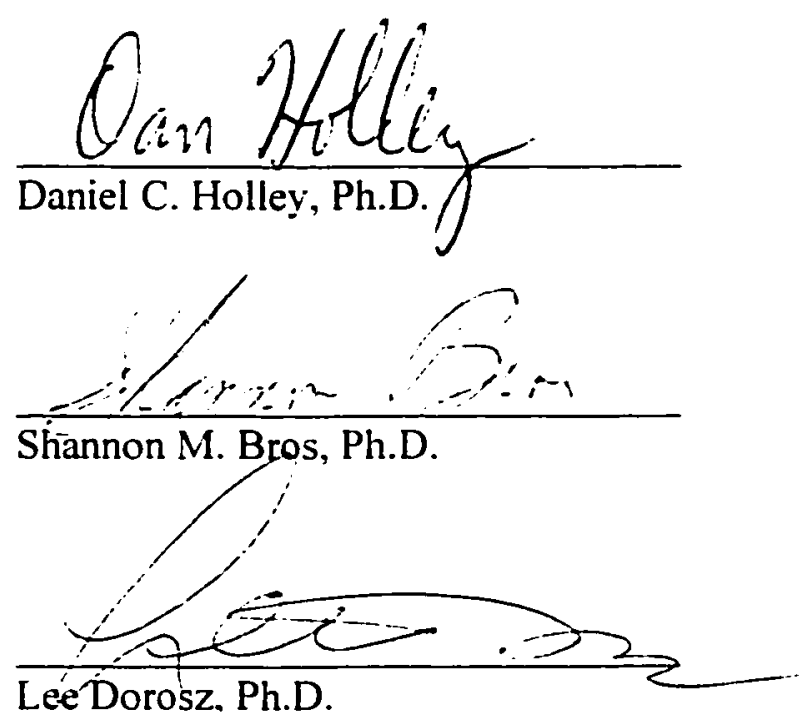

APPROVED FOR THE UNIVERSITY

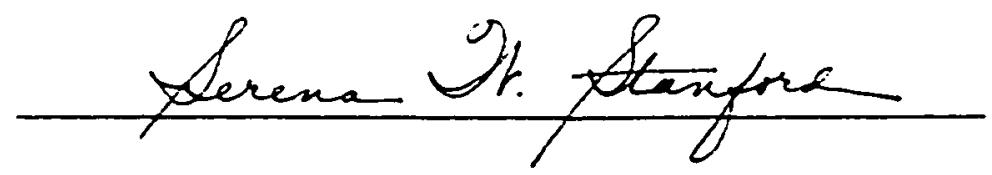




\title{
ABSTRACT \\ COMPARISON OF THROMBOLYTIC THERAPY TO ANGIOPLASTY FOR TREATMENT OF ACUTE MYOCARDIAL INFARCTION
}

\author{
by Joy E. Morris
}

Two commonly used treatments for acute myocardial infarction were compared by meta-analysis. Given two similar study populations, treatment was evaluated for safety and efficacy by analyzing the equality between the two populations, using chi square analysis. The criteria for treatment success were measured in: 1) time to reperfusion, 2) survival past one year, and 3) adverse events or complications. Reperfusion success was measured in minutes from onset of entrance to the emergency room until time to relief of symptoms. Survival, adverse events, or complications were analyzed individually.

The time to relief of symptoms for Global Utilization of Streptokinase and Tissue Plasminogen Activator (GUSTO) was on average 360 minutes versus Primary Angioplasty Registry (PAR) at 27.6 minutes. The GUSTO patients were found to be at higher risk for ischemia and stroke due to the delay in time to achieving patency of the vessels. 


\section{Acknowledgments:}

I would like to acknowledge the contributions of Dr. Dan Holley, Dr. Lee Dorosz. Statisticians: Dr. Shannon Bros, Dr. John Kennedy, and Dr. Frank Dorsey.

I would also like to thank Jeslie Chermak for his patient rereading of numerous drafts. 


\section{TABLE OF CONTENTS}

Page

Abstract

iv

I. Introduction l

$\begin{array}{ll}\text { II. Methods } & 6\end{array}$

$\begin{array}{ll}\text { III. Results: } & 11\end{array}$

Table 1: Demographics \& Presenting Risk Factors 13

Table 2: Efficacy Treatment Outcomes $\quad 14$

$\begin{array}{lr}\text { IV. Discussion } & 15\end{array}$

$\begin{array}{lr}\text { V. References } & 16\end{array}$

Appendix: Definitions 21 


\section{Introduction:}

Myocardial infarction is one of the leading causes of death in the United States; $60 \%$ of afflicted people die within the first hour (23). Those who survive need immediate treatment or their condition usually deteriorates. The typical patient entering an emergency room with acute myocardial infarction (AMI) often presents with intolerable crushing chest pain or referred pain in the extremities. Without treatment the pain continues and infarction and necrosis become substantial. Myocardial infarction occurs in the heart tussue near blocked coronary arteries. An obstruction in a coronary artery can impede oxygen transportation to the cardiac tissue leading to tissue necrosis (infarct). Immediate treatment is crucial to assure recovery from AMI with the fewest complications.

Arteriosclerosis is a common arterial disorder characterized by the thickening, loss of elasticity, and calcification, of arterial walls. Atherosclerosis is characterized by plaques of cholesterol, lipids, and cellular debris in the inner layers of the arterial walls (20). Plaque within the arteries is complicated by platelet aggregation, thrombus formation and spasm. Conditions and prognosticating habits which are correlated with arterial wall damage include: high blood pressure, smoking, poor diet, and lack of exercise. Currently, a coronary infarct patient receives a variety of treatments; two of the most common treatments are 1) dilatation of the infarcted or occluded artery or arteries (balloon angioplasty), and 2) drug therapy to lyse the thrombus obstructing the artery (thrombolytic therapy). 
In angioplasty the coronary artery is accessed via the femoral or brachial artery through the aorta into the coronary ostium. The obstructed artery is visualized with a fluoroscope system and radiopaque medium. A small balloon catheter is tracked to the area targeted for dilation. The balloon is inflated for up to several minutes to compress the obstructive material and create a larger lumen for better blood flow. This procedure disrupts the cellular surface of the vessel walls. In some people this disruption can stimulate production and proliferation of the smooth muscle tissue lining the vessel wall which recreates a narrowing of the lumen called restenosis. Restenosis is one of the potential adverse consequences of angioplasty $(11,23)$.

Thrombolytic therapy is treatment with drugs such as streptokinase or tissue plasminogen activator (t-PA) which act specifically to lyse thrombin, thus preventing fibrin (a key element of thrombus) from accumulating. The use of these drugs include risk of reocclusion, reinfarction, recurrent ischemia, and hemorrhage (intracranial stroke being the more disabling) (30). It should be noted that some of these same risks are also found with angioplasty. Doctors treating patients with thrombolytic regimens attempt to find the most effective combination of thrombolytic and anti-coagulation medications and administer them as early as possible. At times, thrombolytic therapy fails to achieve patency of the infarct-related artery; this decreases the survival outcome. In turn, early patency is associated with improved prognosis (28).

There have been many medical studies on the different treatments available to treat AMI patients today. Deciding which treatment is the safest and most effective is left 
to the physician discretion. Muller and Topol (21) conducted a study of 288 patients who were treated conservatively with thrombolytic therapy. Subjects were observed closely for four days post treatment. Nineteen percent required urgent cardiac catheterization within twenty-four hours, and another $26 \%$ required cardiac catheterization within the next four days. Through multiple regression analysis they found that age and location of the AMI were the primary influences resulting in urgent catheterization. They also found that different thrombolytic therapy treatments influenced the outcomes of these patients.

Thrombolytic therapy has been studied extensively, evaluating dosing and time, to ascertain the most effective administration of anti-coagulants. Sleight (30), in an independent study of thrombolytic therapy evaluating the impact of age and gender, found the mortality rate for elderly female patients was higher than that of men. This was verified by Weaver et al. in a study which compared women and men in treatment for myocardial infarction with thrombolytic therapies (34).

The interventional cardiologist must analyze each patient's condition to decide on the safest course of treatment. Previous studies of these interventional treatments were designed to aid in understanding the mechanisms leading to reperfusion. The goal of each treatment is to effectively and quickly relieve the patient of symptoms. The treatment should establish adequate blood flow in the shortest period of time with freedom from side effects. Inadequate initial myocardial reperfusion in patients with cardiac failure may necessitate further reperfusion treatment, thus increasing the potential for cardiac rupture or increased risk of intracranial hemorrhage. 
When considering interventional treatments several questions surface. For patients treated within the first 24 hours, long term outcomes are an indication of efficacy $(2,21,22)$. Which treatment is the safest and most effective for acute myocardial infarction, angioplasty or thrombolytic therapy? The implications of early rather than late treatment must be considered. Assessment of the efficacy of thrombolytic therapy versus angioplasty can be made through evaluation of relative frequencies of occurrences of adverse events such as repeat MI, emergency surgery, or death.

There are many variables that can affect the outcome of the AMI patient. Yusuf et al. (36) reviewed 33 randomized controlled trials for thrombolytic therapy. It was shown that failure to achieve reperfusion resulted in $10-30 \%$ reocclusion. Yusuf et al. made the point that other contributing factors must be considered, such as anatomic characteristics and the lesion residual; they also demonstrated that time to treatment is an important concern $(18,36)$. Yuhji et al. in Japan confirmed the influence of anatomic characterization, showing that rupture of atherosclerotic plaque was present in over $50 \%$ of the infarct-related arteries, which can influence reocclusion and prognosis $(28,35)$.

O'Neill, a principal investigator for the PAR angioplasty registry, proposed doing a large scale clinical trial to compare angioplasty with thrombolytic therapy $(9,23)$. This direct comparison of angioplasty and thrombolytic therapy has never been performed. thus necessitating the type of analysis performed in this paper.

"Clinical Trials" are conducted to establish safety and effectiveness for drugs and medical therapies before Food and Drug Administration (FDA) approval. These trials 
occur in the United States and in other countries in order to obtain population diversity. The FDA regulations and guidelines were developed to assure study validity and to protect the patient. Medical research companies sponsor these trials to gain FDA approval and subsequently to market their products.

The clinical trials used in evaluating drugs and therapies are done in three phases. In phase I, the primary focus is to obtain safety information related to complications and side effects in humans. Information obtained prior to phase I is usually obtained from animal studies. In phase I, a few human patients are selected for study. It is here that the first side effects may be noticed. Phase II is still safety oriented, yet constructed to look more at doses and time, and how well the treatment works (7). Phase III trials involve a large number of patients and many different study sites. This final phase is conducted to obtain statistical significance for marketing approval. Controls must be included to take into consideration any placebo effect. At times it is necessary to blind the investigators to the treatment being administered so as not to bias the information being gathered.

After phase testing and approval, post market studies are conducted to understand more about study treatment benefits and side effects or adverse events. These studies have fewer controls, and data can be less reliable.

This paper compares two phase III clinica! trials of primary immediate treatments for acute myocardial infarction (AMI). The factors to be considered when comparing two primary treatments for evaluation are safety and efficacy. Therapeutic safety and efficacy 
will be examined for acute (AMI occurring less than 30 days) and non-acute (AMI occurring greater than 30 days) patients over a time period no longer than 365 days.

\section{Methods}

Two phase III clinical trials provided data for this project: the Primary Angioplasty Registry (PAR) (23), and a thrombolytic trial, Global Utilization of Streptokinase and Tissue Plasminogen Activator for Occluded Arteries (GUSTO) (14). The hospitals across the United States that participated used an Investigational Review Board (IRB) to evaluate and qualify patients to participate in the studies by meeting criteria set by the "research institute" and study sponsor. Once a hospital became a participant, patients were selected according to the study criteria through the use of a questionnaire. When the patients met the entrance criteria, they were enrolled in the study and all data relating to the patients, their treatment, and clinical outcomes, including a follow-up survey, were sent to the sponsor. In the angioplasty and thrombolytic trials, the data were sent to Duke University for analysis and archiving (14). The patients' identities were kept confidential. The data used for the current project was limited to hospitals in the United States $(n=271$ patients in the angioplasty study, and $n=310$ patients in the thrombolytic study).

In the angioplasty and thrombolytic clinical trials the patients presented with symptoms of myocardial infarction. Diagnosis included electrocardiography. If the patient showed elevated ST segments, the hospital staff considered the person a potential 
candidate for the clinical trial (4). Patients entered in a trial reflect a combination of clinical features, such as family history for coronary artery disease or high blood pressure, which influence prognosis. To assess risk, these factors must be appropriately weighted. Although a few variables contain most of the prognostic information, other variables contribute independent prognostic information such as age and gender (14).

The variables that were collected on the patients in the thrombolytic and angioplasty studies were not identical because of the intended differences in treatment and different corporate sponsors. This restricted the number of variables when comparing angioplasty versus thrombolytic clinical trials. Not all variables were used in the current analysis; for example, the blood pressure taken upon admission to the hospital is not a reliable means of determining clinically defined hypertension. Bias may be introduced by obtaining cardiovascular medical history from family rather than from medical records. However, with proper training of the staff who interact with the patients being screened, the information may be obtained in a reliable manner. The time criterion before entering the hospital differs among the two treatments: 6 hours post infarct (thrombolytic) versus 12 hours post infarct (angioplasty).

Global Utilization of Streptokinase for Occluded Arteries (GUSTO-1) clinical trial included 41.021 patients with AMI from 1,081 hospitals in 15 countries (8). It was a trial for comparison of four aggressive thrombolytic strategies for AMI. The thrombolytic patients were randomized into the following treatment groups: a.) Streptokinase with I.V. Heparin, b.) Streptokinase with Subcutaneous Heparin, 
c.) Streptokinase with tissue-plasminogen activator, and d.) Tissue-plasminogen activator alone (8). Baseline clinical descriptions were collected on patients as they were enrolled in the study. Variables examined included demographics, history, risk factors, presenting characteristics, and outcomes $(1,9,29)$. The thrombolytic data base with the four combined treatments used in this paper consisted of 310 patients within the United States.

Thrombolytic patient eligibility criteria were minimum 18 years of age and presenting with symptoms of AMI. The electrocardiogram must have shown elevated ST segments. Onset of the patient symptoms must have been less than 6 hours from time of presentation. The hospital staff was responsible for screening, enrollment and subsequent randomization into one of the four angioplasty treatment groups. Patients were eliminated from the study if they had a history of stroke, active or recent bleeding, history or major coagulation abnormality, recent trauma or major surgery, noncompressible vascular punctures, and previous treatment with streptokinase or anistreplase (because of possible allergic reactions). There were no restrictions placed on the upper age limit. Patients were excluded for presentation with cardiogenic shock, prior bypass surgery, major surgery or organ biopsy within 2 months, or severe hypertension. $(8,9)$.

The Primary Angioplasty Registry (PAR) study was a multi-center clinical trial for AMI patients within 12 isurs of symptom onset who were eligible for percutaneous transluminal coronary angioplasty (PTCA), which is balloon inflation of the blocked coronary artery. Admitting information included baseline clinical descriptions of patients 
as they were enrolled in the study, including demographics, history, risk factors, presenting characteristics, and outcomes. Details of the angioplasty treatments, and heparin use were also recorded. The PAR clinical trial was actually designed to be comparable to the GUSTO thrombolytic clinical trial that was ongoing at the time (23). However. no direct comparison of the two trials was ever performed.

Angioplasty patient eligibility criteria were minimum 18 years of age presenting with symptoms of AMI. A 12 lead electrocardiogram must have shown elevated ST segment. Onset of symptoms was less than 12 hours before entry to the hospital and there was no history of proclivity for bleeding. Patients with prior bypass grafting were included in the study. Patients were excluded from angioplasty under the following conditions: left main coronary arterial stenosis or infarct artery stenosis was $\leq 50 \%$, inability to identify the infarct related artery, extremely long or angulated infarct lesion, or small or extremely tortuous infarct artery (23).

Pretreatment protocol included nasal oxygen, with 10,000 units of heparin intravenously; analgesics and beta blockers were left to the individual investigator's discretion. A second bolus of 10,000 units of heparin was administered after coronary arterial access was obtained. ACTs (activated clotting times) were maintained through heparin dosing at $>300$ seconds. Ejection fractions were measured via echocardiogram (23). 


\section{Statistical Methods:}

Standard meta-analysis techniques were used to determine if the demographics of the thrombolytic study group (GUSTO) and the angioplasty group (PAR) were equivalent $(5,10)$. Comparative meta-analysis was used when treatment groups were from different studies in which the populations of patients were similar but not identical $(5,36)$. Chisquare tests were used to test for equality of proportions for each of the categorical variables among the two study groups (19).

Both discrete and continuous variables were used to compare efficacy and safety parameters between the patients in the thrombolytic group and the angioplasty group. Meta-analysis was used for discrete variables such as gender, presenting risk factors and complications. One decision marker used for evaluating efficacy was time: (how quickly the patient was relieved of symptoms). Efficacy was also evaluated by frequency of death within a population. Safety was the other marker used in evaluating the probability of adverse events. The hypothesis tested for efficacy was the analysis of time from entrance into the emergency room to relief of symptoms as assessed by the treating physician. Symptoms included chest pain as the principal indicator; for confirmation the patient was examined for elevated ST segments in the ECG. To minimize the chance of incorrectly rejecting Ho (Type I error), an alpha level of 0.025 was selected for all comparisons. 
The nonparametric Mann-Whitney U-test (37) was used to indicate the significance of lower time-to-relief of symptoms in comparing the two studies. Time is a continuous variable and therefore not appropriate for a chi-square test.

\section{Results}

Comparative Meta-Analysis:

The results of the meta-analysis indicated that patient parameters of the two study groups were compatible. There were no significant differences in demographic parameters between the thrombolytic group and the angioplasty group; patient age range for both studies was 25 years to 76 years and $53 \%$ of those patients were $46-65$ years of age. Greater than $72 \%$ of the populations were men and greater than $25 \%$ were women. Risk factors were also comparable $(p=0.824)$, as were complications $(p=0.555)$.

Efficacy, as measured by number of deaths attributed to the disease, did not differ among the two types of treatments. The chi-square test indicated no significant difference $(p=0.143)$ in death rates. The nonparametric Mann-Whitney U-test showed a statistical significance $(p<0.001)$ in the time to relief variable. The thrombolytic group had an average time of 360 minutes (6 hours); the overall range of time was 180-360 minutes ( 3 to 6 hours). The angioplasty group had an average time of 27.6 minutes to relief; the overall range of time was 30 to 90 minutes.

Safety was evaluated through adverse events such as ischemia, bleeds, stroke, and reinfarction (Table 2). Complications such as ischemia were found to be more significant in the thrombolytic patients (at 20\%) compared to the angioplasty patients (at $12.5 \%$ ). 
Severe bleeds had a higher percentage rate for the angioplasty group (4.8\%), whereas the thrombolytic population was (1\%). Stroke for the thrombolytic group was (3.5\%), and for the angioplasty group, (1.5\%). Reinfarction for the thrombolytic group was (4.5\%), and for the angioplasty group, (7\%). The remaining adverse events such as arrhythmias, hypotension and tamponades were not found to differ significantly. 


\section{Table 1}

Baseline Demographics and presenting Risk Factors:

Comparison of Treatment Groups:

Cross Tabulations:

Total Number of Patients

GUSTO
310

$<25$ years old $25-45$ years old $46-65$ years old $66-75$ years old

Gender

$\geq 76$ years old

Risk Factors

$\begin{array}{rc}\text { Male } & 226 \\ \text { Female } & 84\end{array}$

30

162

77

41

226 84

50

85

145

162
Diabetes

Current Smoker

Current/Historic Smoker

Family History of CVD*

Complications

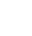

7

1

$10 \%$
$52 \%$
$25 \%$
$13 \%$

$73 \%$

$27 \%$

$16 \%$

$27 \%$

$47 \%$

$54 \%$
PAR
271

0

35

145

65

26

201

70

38

80

116

134
Chi-Square

$p=0.3773$

$13 \%$

$53 \%$

$24 \%$

$10 \%$

$74 \%$

$26 \%$

$14 \%$

$30 \%$

$43 \%$

$55 \%$

$$
p=0.8019
$$$$
p=0.824
$$

$p=0.555$

\footnotetext{
- Cardiovascular Disease
}

Adverse Events and complications are compared between GUSTO and PAR in

Table 2 below. Under total and percentage are the " $n$ " and relative percentage rates

respectively. The dates of the events were recorded for each patient, this information was

broken down into acute and non-acute. If data are missing on patients; this is listed under

the missing data column with an asterisk for all data present, and a number representing

missing or unknown information. In certain cases dates are known for the event; if the

dates are missing for that event it is tallied and represented under dates unknown. All

abbreviations are noted in the Appendix on page 27. 
Table 2

Efficacy Treatment Outcomes:

Complications

Stroke

Ischemia

Reinfarction

GUSTO

PAR

PTCA

ERPTCA

URPTCA

Atrial/Vent.

Block

GUSTO

PAR

65

245

GUSTO

PAR

26

II

GUSTO

PAR

GUSTO

PAR

GUSTO

SV Tach

Tachycardia

PAR

V FIB

Fibrillation

GUSTO

PAR

17

20

Tamponade

GUSTO 3

PAR

Atrial Fib

Fibrillation

GUSTO 32

PAR

37

Hypotension

GUSTO

PAR

37

29

Moderate Bleed

GUSTO 30

PAR

41

Severe Bleed

GUSTO

PAR

3
13

\section{Total Percentage}

$$
\text { \# of }
$$

atients

4

$3.5 \%$

$1.5 \%$

$20 \%$

$12.5 \%$

$4.5 \%$

$7 \%$

Acute

$\leq 30$

*

4

Non-

Acute

$\geq 30$

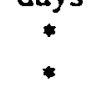

* 62

$*$

24

14

7

$21 \%$

$90 \%$

$8 \%$

$4 \%$

Missing

Data

Dates

Unknown

11

$p=0.1905$

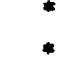

2

*

$p=0.0214$

10

$p=0.3065$

$p=<0.0001$

$p=0.0499$

$\begin{array}{llll}* & 0 & * & 100 \\ 15 \% & 4 & * & \end{array}$

$p=0.1003$

$p=0.9325$

$\begin{array}{llll}8.7 \% & * & * & \\ 8.8 \% & * & 0\end{array}$

$p=0.5557$

$p=0.4452$

$7.4 \% \quad * \quad * \quad 0$

$\begin{array}{llll}1 \% & * & * & 2 \\ 0.4 \% & * & * & 0\end{array}$

$10 \% \quad * \quad *$

$13.6 \%$

$12 \%$

$11 \%$

$10 \%$

$15 \%$
$1 \%$
$4.8 \%$

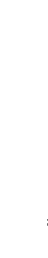

$$
p=0.7130
$$$$
p=0.2672
$$$$
p=0.7363
$$$$
p=0.0608
$$

$p=0.0105$ 


\section{Discussion:}

Comparative meta-analysis techniques were used in evaluating the two study groups: AMI patients treated with thrombolytics, and AMI patients treated with angioplasty. The populations were compared and found to be equivalent. The demographics (variables) were also analyzed and found to have no statistical difference. Relationships among the variables were found to be independent, thus making the comparison uncomplicated.

In the evaluation of safety, the majority of deaths that occurred were within the first 30 days after treatment $(14,22)$. However, overall mortality was low: angioplasty was $3.7 \%$ and thrombolytic therapy was $6.8 \%$. The difference was not statistically significant.

It remains in the doctor's judgment to decide which treatment most appropriately meets the needs of a given patient. There is no statistical model to predict probability of treatment success. The prevailing symptoms for any one person are always different, making choice of treatment less absolute. The only factor to help in such a decision is when one treatment is more quick acting than another. Time to relief of symptoms will have some influence on choice. An example of this is treatment with t-PA: an initial bolus is given over a one hour period of time to avoid hypotension. Promoting a lytic state with a drug takes longer to achieve. explaining why the time to relief is longer for the drug treated patient. The current study showed that the patients treated with angioplasty had relief sooner than those treated with thrombolytic therapy. The sooner 
the patient's treatment was effective, the less risk to the myocardial tissue, and the better the patient's outcome. This has also been shown in other studies that looked at trends in terms of time to treatment $(14,29)$.

Improving survival is the goal of each treatment, so survival by itself becomes a factor in deciding treatment, with the goal to reperfuse early and promote health. The death rate was very low, therefore complications became the focus of outcome. Unsuccessful reperfusion of the myocardium or failure to maintain arterial patency was associated more closely with complications. Ischemia occurred in $20 \%$ of thrombolytic patients, and $12.5 \%$ of angioplasty patients (Table 2). Ischemic patients needed followup secondary treatment.

In summary, angioplasty patients had quicker relief from their AMI symptoms than did thrombolytic patients. Prolonging relief (as in the thrombolytic treatment which required waiting for the systemic mechanism to create patency) results in a higher risk of ischemia. Ischemia or stroke in turn leads to other undesirable complications. 


\section{References:}

1. Collen, Desire, Lijnen, Henri, R.; On the Future of Thrombolytic Therapy for Acute Myocardial Infarction. The American Journal of Cardiology. 72:48G - 50G, 1993

2. Barbagelata, A., Granger, C., Topol, E., Worley, S.J., Kereiakes, D.J., George, B.S., Ohman, E.M., Leimberger, J.D., Mark, D.B., Califf, R.M.; Frequency, Significance, and Cost of Recurrent Ischemia After Thrombolytic Therapy for Acute Myocardial Infarction. American Journal of Cardiology. 76:1007 - 1013, 1995

3. De Servi, S., Eleuteri E., Bramucci, E., Valentini, P., Angoli, L., Marsico, F., Kubica, J., Costante, A.M., Barberis, P., Mariani, G., Specchia, G.; Effects of Coronary Angioplasty on Left Ventricular Function. The American Journal of Cardiology. 72:119G - 123G, 1993

4. Dissmann, Rudiger; Schroder, R. Busse, U., Appel, M., Bruggemann, T., Jereczek, M., Linderer, T.; Early assessment of outcome by ST-Segment analysis after thrombolytic therapy in acute myocardial infarction. American Heart Journal. 128:5: $851-857,1994$

5. Friedman L.M., Furberg, C.D., DeMets D.L.; Clinical Trials. Third Edition, pages $310-316,1996$

6. Greenberg, Raymond Daniels, S.R., Flanders, W.D., Eley, J.W., Boring, J.R.; Medical Epidemiology. First Edition, Appleton and Lange, 127 pp, 1993

7. Giffels, Joseph J., Clinical Trials. First Edition, Demos Vermande, New York, pages $7-11,1996$

8. Gore J.M., Granger C.B., Simoons M.L., Sloan, M.A., Weaver, D., White, H.D., Barbash, G.I., Van de Werf, Frans, Aylward, P.E., Topol, E.J., Califf, R.M.; Stroke After Thrombolysis, Mortality and Functional Outcomes I: The GUSTO-I Trial. Circulation. 92:10: 2811 - 2818, 1995

9. Hassle, Astra AB, What's What. Third Edition, Sweden, pages $116-117,1996$

10. Honan, Michael, Harrell, F., Reimer, K.A., Califf, R.M., Mark, D., Pryor, D.B., Hlatky, M.A.; et al; Cardiac Rupture, Mortality and the Timing of Thrombolytic Therapy: A Meta-Analysis. American College of Cardiology. 16:2:359 - 367, 1990 
11. Kern, Morton; The Cardiac Catheterization Handbook. First Edition, pages 470 478,1991

12. Kloner R.A. (editor) The Guide to Cardiology. Second Edition, Le Jacq Communications. pages 207 - 239, 1990

13. Langer A., Krucoff M.W., Klootwijk, P., Veldkamp, R., Simoons, M.L., Granger, C. Califf, R.M., Armstrong, P.W., Noninvasive Assessment of Speed and Stability of Infarct-Related Artery Reperfusion: Results of the GUSTO ST Segment Monitoring Study. Journal of the American College of Cardiology. 25:7: 1552 - 1557, 1995

14. Lee, Kerry; Woodlief, Lynn; Topol E., Weaver, W.D., Betriu, A., Col, J., Simoons, M.L., Aylward, P. Van der Werf, F., Califf, R.M.; Predictors of 30-Day Mortality in the Era of Reperfusion for Acute Myocardial Infarction. Circulation. 91:6, 16591668,1995

15. Lee, Veronica, L.; Initial Experience with Hirudin and Streptokinase in Acute Myocardial Infarction: Results of the Thrombolysis in Myocardial Infarction (TIMI) 6 Trial. American Journal of Cardiology. 75: 7 - 13, 1995

16. Lincoff, M.A.; Topol E., Ellis, S.G.; Local Drug Delivery for the Prevention of Restenosis. Circulation. 90:4: 2070 - 2084, 1994

17. Lynch, Mary, Pentecost, B.L., Littler, A., Stockley, R.A.; Overt and Subclinical Reaction to Streptokinase in Acute Myocardial Infarction. American Journal of Cardiology. 74: 849 - 852, 1994

18. Merlini, P.A., Cattaneo, M., Spinola, A., Ardissino, D., Oltrona, L., Belli, C., Mannucci, P.M.; Activation of the Hemostatic System During Thrombolytic Therapy. American Journal of Cardiology. 72: 59G - 65G, 1993

19. Middleton, Michael R. Data Analysis Using Excel 5.0. First Edition, pages 102-103, 127-128, 142-148, 1995

20. Mosby's Medical, Nursing, and Allied Health Dictionary. Third Edition. CV Mosby Co., St. Louis, 1990

21. Muller, David; Topol E., Ellis, S., Woodlief, L.H., Sigmon, K.N., Kereiakes, D.J., George, B.S., Worley, S.J., Samaha, J.K., Philips, H., Califf, R.M.; Determinants of the Need for Early Acute Intervention in Patients Treated Conservatively After Thrombolytic Therapy for Acute Myocardial Infarction. American College of Cardiology. 18:7: 1594-1601, 1991 
22. Ohman E.M., Topol E.J., Califf R.M., Bates, E.R., Ellis, S.G., Kereiakes D.J., George, B.S., Samaha, J.K., Kline, E., Sigmon, K.N., Stack, R.S.; An analysis of the cause of early mortality after administration of thrombolytic therapy. Coronary Artery Disease. $4: 11: 957-964,1993$

23. O’Neill, William, Brodie, B.R., Ivanhow, R., Knopf, W., Taylor, G., O’Keefe, J., Grines, C.L., Weintraub, R., Sickinger, B.G., Berdan, L.G., Tcheng, J.E., Woodlief, L.H., Strzelecki, M., Hartzler, G., Califf, R.M., Primary Coronary Angioplasty for Acute Myocardial Infarction (The Primary Angioplasty Registry), The American Journal of Cardiology. 73:9: 627 - 634, 1996

24. Pompa, J.J.; Califf, R.M., Ellis, S.G., George, B.S., Kereiakes, D.J., Samaha, J.K., Worley, S.J., Anderson, J.L., Stump, D., Woodlief, L., Sigmon, K., Wall, T.C., Topol, E.J.; Mechanism of Benefit of Combination Thrombolytic Therapy for Acute Myocardial Infarction: A Quantitative Angiographic and Hematologic Study. American College of Cardiology. 20:6: 1305-1312, 1992

25. Prentice, Colin R.M.; Antithrombolytic Therapy in the Secondary Prevention of Myocardial Infarction. American Journal of Cardiology. 72: 175G - 180G, 1993

26. Rapaport Elliot, Thrombolysis, Anticoagulation, and Reocclusion. American Journal of Cardiology. 67: 17E - 22E, 1991

27. Riegelman R.K., Hirsch R. P., Studying a Study and Testing a Test. Second Edition Little, Brown and Company, pages $93-115,269-277,1989$

28. Steg P.G., Karrillon G.J., Himbert, D., Juliard, J.M., Rescue Angioplasty in Acute Myocardial Infarction. CARDIO. pages $37-46,1994$

29. Simes, R.J.; Topol E., Holmes, D.R. Jr., White H.D., Rutsch, W.R., Vahanian, A., Simoons, M.L., Morris, D., Betriu, A., Califf R.M.; Link Between the Angiographic Substudy and Mortality Outcomes in a Large Randomized Trial of Myocardial Reperfusion: Importance of Early and Complete Infarct Artery Reperfusion. Circulation. 91:7: 1923 - 1928, 1995

30. Sleight, Peter; Is there an Age Limit for Thrombolytic Therapy? The American Journal of Cardiology. 72: 30G - 33G, 1993

31. Tabachnick B.G., Fidell L.S. Using Multivariate Statistics. Third Edition, Harper Collins College Publishers, pages 575 - 594, 1996 
32. Davis, F.A.; Taber's Medical Dictionary. $17^{\text {th }}$ Edition, Philadelphia, (Definitions) 1989

33. Wall, Thomas, Califf, Robert, Ellis, S.G. Sigmon, K., Kereiakes, D., George, B.S., Samaha, J., Sane, D., Stump, D.C., Stack, R., Topol, E.J.; Lack of Impact of Early Catheterization and Fibrin Specificity on Bleeding Complications After Thrombolytic Therapy. The American College of Cardiology. 21:3: 597 - 603, 1993

34. Weaver W.D., White H.D., Wilcox R.G., Aylward, P.E., Morris, D., Guerci, A., Ohman, M., Barbash, G., Betriu, A., Zygmunt, S., Topol, E.J., Califf, R.M.; Comparisons of Characteristics and Outcomes Among Women and Men with Acute Myocardial Infarction Treated with Thrombolytic Therapy. Journal of American Medical Association. 275:10: 777 - 782, 1996

35. Yuhji, Hanada, Yasushi Koiwaya, Tanaka, K.; Coronary Angiographic Findings in Infarct-Related Arteries Following I Month of Medical Treatment. Cardiovascular Intervention Radiology, 17: 87 - 94, 1994

36. Yusuf S., Collins, R., Peto, R., Furberg, C., Stampfers, M.J., Goldhaber, S.Z., Hennekens, C.H.; Intravenous and intracoronary fibrinolytic therapy in acute myocardial infarction: Overview of results on Mortality, reinfarction and side-effects from 33 randomized controlled trials. European Heart Journal. 6:556 - 585, 1985

37. Zar, J.H., Biostatistical Analysis. Third Edition, Prentice Hall, New Jersey, 783pp., 1996 


\section{APPENDIX}

Definitions:

- Acute Myocardial Infarction: Loss of blood flow to the cardiovascular tissue causing necrosis (heart antack).

- Angiography: Fluoroscopic study of the heart.

- Atrial Fib: Atrial Fibrillation. Extremely rapid, incomplete contractions of the atria resulting in rapid uncoordinated movement of the heart.

- Atroven: Atrial ventricular electrical block. Blockage of electrical conduction through the AV node.

- ERPTCA: Emergent PTCA.

- Hypotension: Low blood pressure.

- Ischemia: Insufficient blood supply to the heart muscle due to obstruction.

- Necrosis: Tissue death.

- Patency: An open vessel or arterial way.

- PTCA: Percutaneous transluminal coronary angioplasty.

- Reinfarction: Recurrent myocardial infarction.

- Reoccluded : The artery has lost patency.

- Stroke: Occlusion of an artery due to hemorrhage, embolus or thrombus.

- Surgery: (CABG): Coronary artery bypass graft.

- SV Tach: Supraventricular Tachycardia. Abnormal rapid heart rate, defined as over 100 beats per minute.

- Tamponade: Fluid in the pericardium. (Blood leaking from the heart chamber into the pericardium.)

- Timi: Thrombolysis in myocardial infarction. This was actually a trial in patency classification.

- URPTCA: Urgent PTCA.

- V Fib: Ventricular Fibrillation. Extremely rapid, incomplete contractions of the ventricle resulting in rapid uncoordinated movement of the heart. 


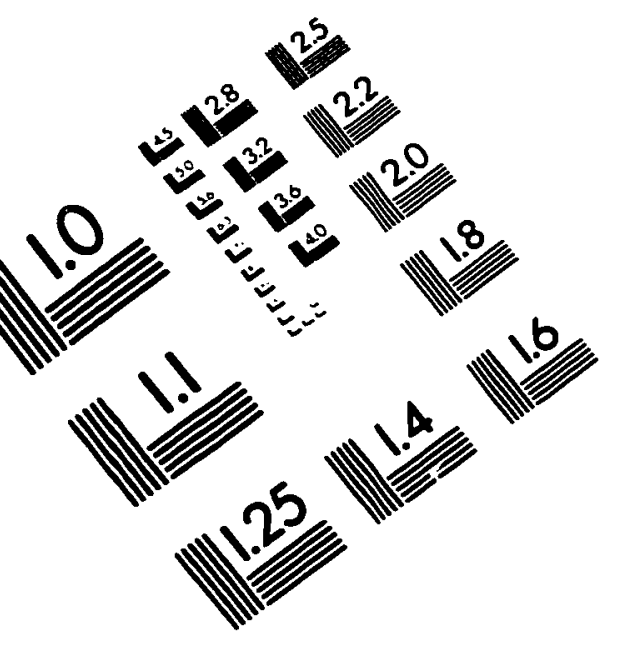
IMAGE EVALUATION
TEST TARGET (QA-3)
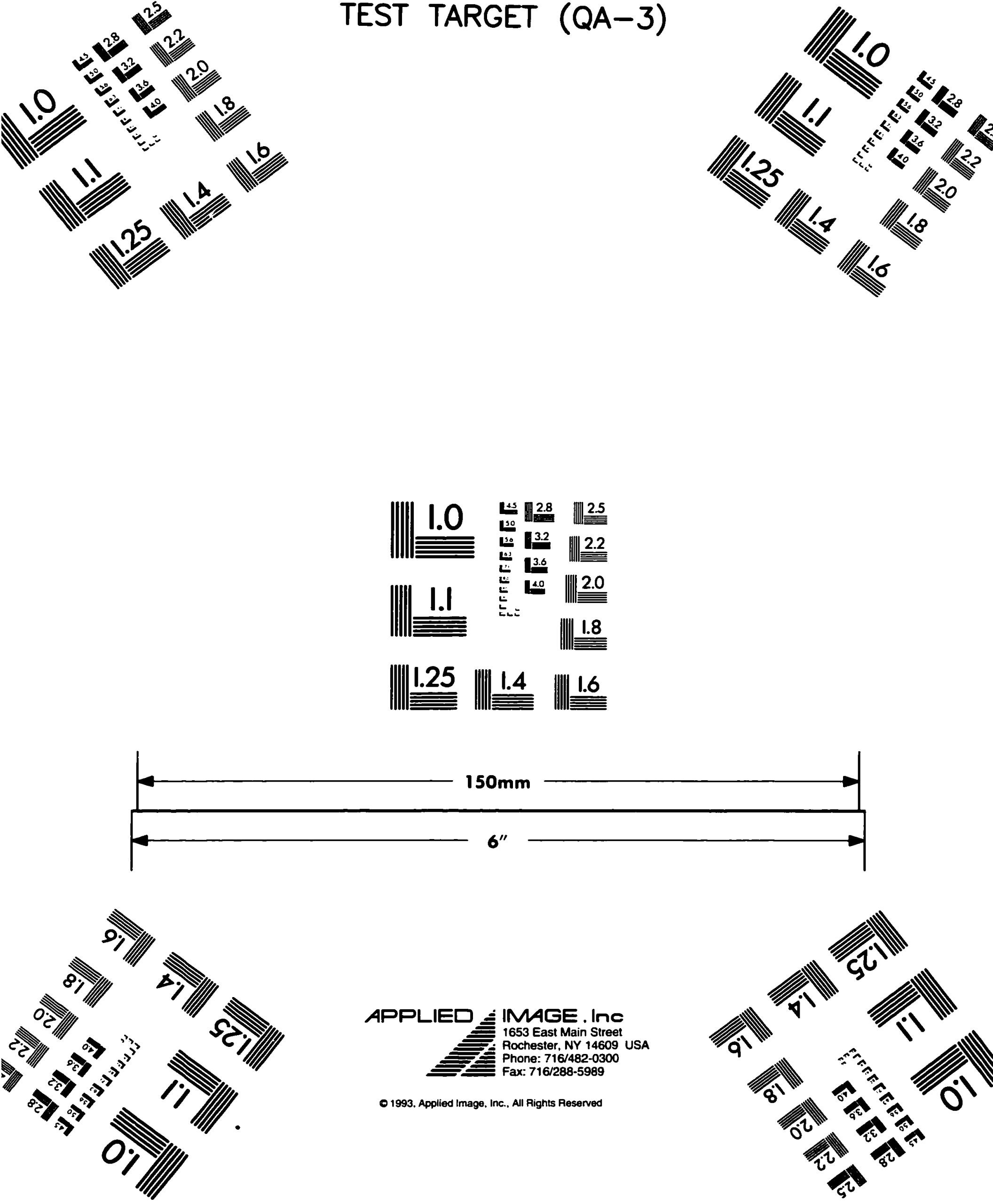